\title{
Towards a re-assessment of the surface mass balance of the Greenland ice sheet
}

\author{
M. van den Broeke ${ }^{1}$, J. Ettema ${ }^{1}$, W.J. van de Berg ${ }^{1}$, and E. van Meijgaard ${ }^{2}$ \\ 1 Institute for Marine and Atmospheric research, Utrecht University, PO Box 8005, 3508 TA Utrecht, \\ The Netherlands \\ 2 Royal Netherlands Meteorological Institute, PO Box 201, 3730 AE De Bilt, The Netherlands
}

\begin{abstract}
At present, the mass balance and especially the surface mass balance of the Greenland Ice Sheet (GrIS) are poorly known. Current methods to determine GrIS surface mass balance as well as the inherent uncertainties are discussed. Special emphasis is placed on the increasingly important role of regional atmospheric climate models, which explicitly calculate the individual components of the surface mass balance: (solid) precipitation, melt and subsequent runoff, sublimation/deposition and refreezing in the snow. Especially the latter term is very uncertain, and poses a great challenge to modellers. Some recent advances in these fields of research are presented.
\end{abstract}

\section{Introduction}

The Greenland ice sheet (GrIS) is the largest freshwater source in the Northern Hemisphere [1]. Large uncertainties remain in the present and future mass balance of the GrIS $[2,3]$ and its contribution to sea level change $[4,5]$. Although it is virtually certain that the GrIS is presently loosing mass, its absolute contribution to global sea level rise and the regional oceanic fresh water budget remains poorly known. Recent estimates of the annual mass loss based on repeat satellite gravimetry [6-9], satellite radar/laser altimetry [10-13] and satellite radar interferometry combined with climate modelling [14] range from $75-227 \mathrm{Gt} \mathrm{yr}^{-1}$ [15]. This is equivalent to a sea level rise of $0.21-0.63 \mathrm{~mm} \mathrm{yr}^{-1}$ and represents a significant fraction of the estimated total sea level rise of $3.1+/-0.7 \mathrm{~mm} \mathrm{yr}^{-1}(1993-2005)$ [16]. The uncertainty in these estimates is for an important part caused by our incomplete knowledge of the surface mass balance (SMB, units $\mathrm{kg} \mathrm{m}^{-2}$ year ${ }^{-1}$ ), the sum of accumulation (snowfall) in the ice sheet interior and ablation (melting and subsequent runoff) at its margins. The main reason for this is the chronic lack of SMB observations from sites with high accumulation (snowfall) and high ablation (melting and subsequent runoff).

The components of the surface mass balance of a snow/ice surface are solid/liquid precipitation $(\mathrm{PR})$, surface sublimation $\left(\mathrm{SU}_{\mathrm{s}}\right)$, melt and subsequent runoff $(\mathrm{RU})$ and processes related to drifting snow, namely erosion due to divergence of the horizontal snow drift transport $\left(\mathrm{ER}_{\mathrm{ds}}\right)$ and sublimation of drifting snow particles in a column extending from the surface to the top of the drifting snow layer $\left(\mathrm{SU}_{\mathrm{ds}}\right)$ :

$$
\mathrm{SMB}=\mathrm{PR}-\mathrm{SU}_{\mathrm{s}}-\mathrm{RU}-\mathrm{ER}_{\mathrm{ds}}-\mathrm{SU}_{\mathrm{ds}} .
$$

In Greenland, measuring these components separately is not an easy task; precipitation gauges do not work well when snow falls under high wind speed conditions, as is often the case, as drifting snow may enter the gauge. That is why to date no reliable estimates of the precipitation distribution over the GrIS exist, even though it is the dominant term in the surface mass balance. Even more complicated to assess is runoff, because it may occur deep in the snow pack. Here 


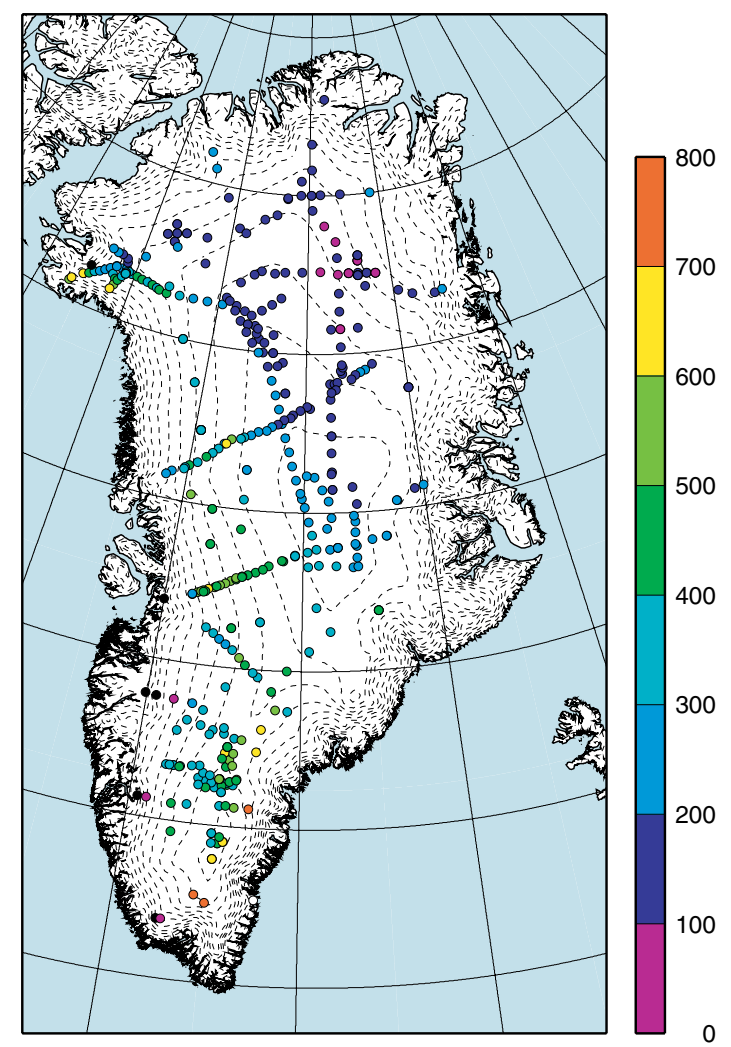

Fig. 1. Selected SMB observations on the Greenland ice sheet in $\mathrm{kg} \mathrm{m}^{-2}$ year ${ }^{-1}$. From [18].

we describe some recent advances in meteorological techniques that are used to assess the SMB of the Greenland ice sheet, with emphasis on regional climate modelling and long-term observations from the ablation zone.

\section{Mass balance observations}

To improve the density of in situ observations and to monitor the near-surface climate and mass balance of the GrIS, automatic weather stations (AWS) are increasingly being used [17]. In addition, numerous ice cores have been drilled, each yielding a local accumulation rate for a certain time period; however this has not led to a sufficiently dense grid of in-situ observations to allow for an accurate determination of the SMB field by interpolation alone. The data in Fig. 1, mainly based on [18], only give a general impression of a wetter southern and western ice sheet and a drier north-eastern ice sheet, with some suggestion of increasing accumulation towards the extreme south and south-eastern ice sheet.

To make matters worse, only very few observations exist from the ablation zone (black dots), where mass is lost on an annual basis (runoff exceeds snowfall) and where balance gradients are largest and recent changes in ice flow have been the most pronounced [19-21]. [22] presented several SMB profiles as a function of elevation from various latitudes in west Greenland, but the time series on which these profiles were based are often very short, i.e. one to several years. The longest uninterrupted time series of SMB from the Greenland ablation zone is the K-transect, a stake array along the $67^{\circ}$ latitude circle in southwest Greenland. It was set up during the Greenland Ice Margin Experiments in 1990 and 1991 (GIMEX-90/91) [23]. With 18 years, it currently represents the longest mass balance time series of its kind in Greenland [24].

As the ablation stakes are measured only once a year, they provide just information about net ablation/accumulation, not separately about winter accumulation and summer melt. To 


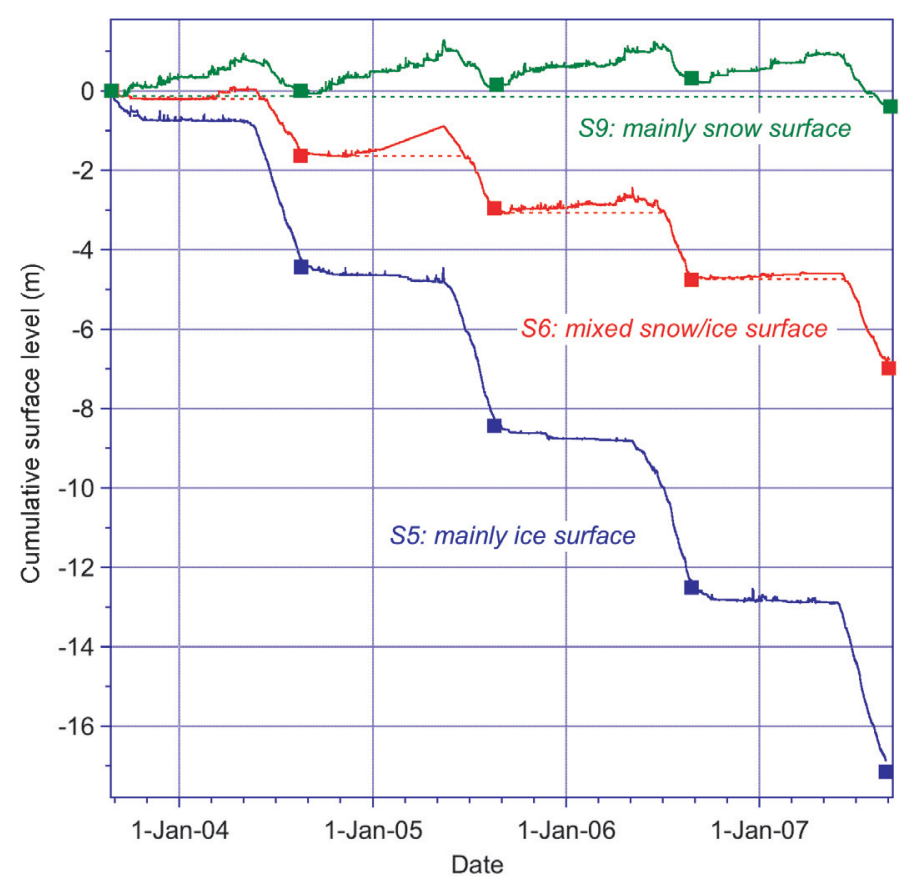

Fig. 2. Observed surface elevation change at three sites along the K-transect at 490 (S5), 1020 (S6) and $1520 \mathrm{~m}$ asl (S9), for the period September 2003 to September 2007. From [25].

improve this, three sites along the K-transect have been equipped with sonic height rangers, to monitor the temporal evolution of the surface height; they were installed at 6,38 and $88 \mathrm{~km}$ from the ice sheet margin at elevations of 490, 1020 and $1520 \mathrm{~m}$ asl in August 2003. Figure 2 shows the measured changes in surface level (August 2003-August 2007) in response to accumulation and ablation processes. At S9, the ablation season lasts about six weeks, which is just sufficient to melt the approximately $1 \mathrm{~m}$ of winter snow; we may conclude that S9 is situated close to the equilibrium line which separates the accumulation from the ablation zone. Only in the warm summer of 2007 did ablation clearly exceed accumulation, placing S9 below the equilibrium line altitude in that year. Surprisingly, the winter accumulation decreases towards the lower sites, until it becomes essentially zero at S5. The most plausible explanation for this is that snow is blown in crevasses and/or sublimated when it is suspended in the air during blowing snow events. This has important implications for the surface mass balance, because the dark ice surface is exposed early in the melting season which enhances the melt rates. At S5 in the lower ablation zone, the ablation season runs from May to September, resulting in a negative SMB of about $4 \mathrm{~m}$ of ice per year. As a result of the accumulation gradients and the enhanced albedo effect, melting and runoff increase exponentially towards the margin of the ice sheet [25]. This further stresses the need for high-resolution mass balance modelling (see next section).

\section{Mass balance models}

To resolve these steep gradients in the narrow ablation zone of the GrIS requires the use of mass balance models with a high ( $\sim 10 \mathrm{~km}$ or better) horizontal resolution. Distributed mass balance models or temperature index models do have the required resolution, but need cloud, radiation and temperature fields to be prescribed [26-28]. Especially for climate change scenarios, this introduces large uncertainties. Conversely, output of global meteorological models includes all the necessary physics but requires downscaling to obtain the desired resolution [29-31]. Moreover, global meteorological models often have poor or lacking representation of processes in the snow cover (albedo, percolation, refreezing). 

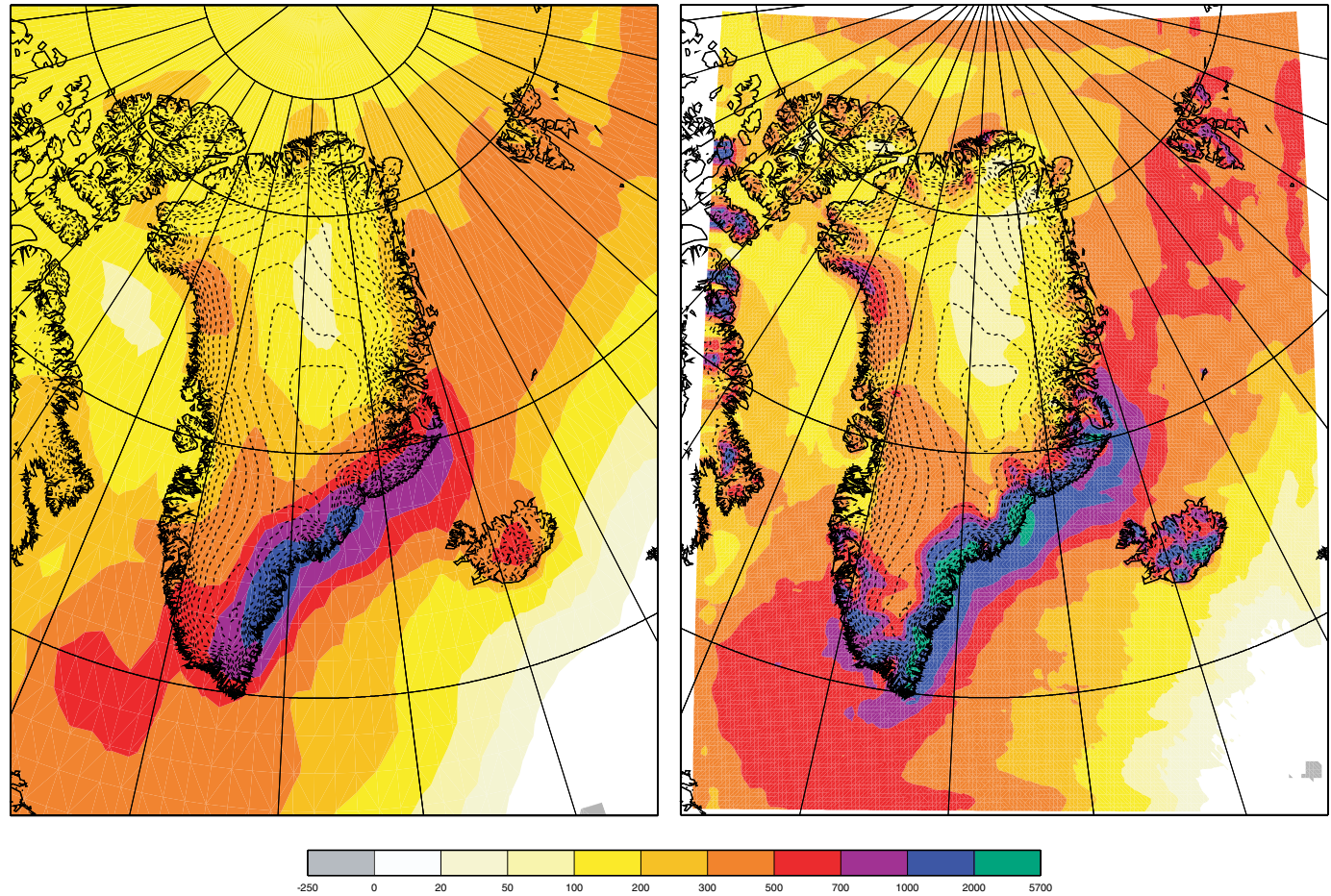

Fig. 3. Solid precipitation in $\mathrm{kg} \mathrm{m}^{-2} \mathrm{yr}^{-1}$ from ERA40 with approximately $100 \mathrm{~km}$ horizontal resolution (left) and a regional atmospheric climate model RACMO2 at $17 \mathrm{~km}$ resolution (right). Note that both figures show the high-resolution topography.

Regional atmospheric climate models do have the right mix of high resolution and realistic physics to study the present-day mass balance of the GrIS [32-35]. To demonstrate the impact of model resolution, Fig. 3 compares the 1992 solid precipitation (snowfall) distribution over Greenland and its surroundings as produced with a global meteorological model in re-analysis mode (European Centre for Medium Range Weather Forecasts Re-analysis 1957-2004, ERA40, about $100 \mathrm{~km}$ horizontal resolution, left frame) to a pilot run with a regional climate model (Regional Atmospheric Climate Model RACMO2, horizontal resolution $17 \mathrm{~km}$, right frame). In the absence of strong insolation, most precipitation in the Polar Regions is caused by forced convection, either by topography or along fronts separating cold polar air masses from warmer subtropical air. The high-resolution model much better resolves the steep coastal topography, resulting in steeper slopes and much enhanced topographically forced precipitation (accumulation) gradients. The high precipitation is confined to a smaller region, nonetheless the total precipitation over the ice sheet increases, by as much as $17 \%$ in this example. Also note that the dry area in northeast Greenland has become more extensive in the high-resolution run.

It is obvious from comparing the two precipitation fields in Fig. 3 that the amount of detail in the high-resolution model can never be reconstructed using downscaling of the low-resolution model, even if the higher-resolution topography is used to redistribute the accumulation; any downscaling is very likely to underestimate the total amount of precipitation on the ice sheet.

These results clearly demonstrate that it is not possible to obtain a realistic SMB distribution over the GrIS based on low-resolution climate modelling, nor that it is very useful to attempt to achieve this using interpolation of available in-situ observations (Fig. 1). When comparing Fig. 3 (right frame) to Fig. 1, it becomes evident that areas with high accumulation are seriously under-sampled in the available observations. The reason is simple: high accumulation areas are more difficult to access owing to the bad climate, poor visibility and deep snow. The same is true for the ablation zone, which is notoriously difficult to navigate, as a result of the uneven surface with 2-3 m high ice hummocks, the ever-changing position of melt rivers and lakes and 
the occurrence of meltwater-saturated snow (slush) in the higher ablation zone. Moreover, ice ablation of several $\mathrm{m}$ per year makes that regular visits are required to avoid stakes from melting out. These repeated observations are therefore relatively much more costly than a single drilling of a shallow firn core in the higher ablation zone, which suffices to obtain an accumulation time series. This is clearly reflected in Fig. 1, which observations concentrated in areas with moderate accumulation values. The under-representation of data from the regions with the highest SMB gradients indicates that any attempt to interpolate/extrapolate the existing data to generate a map of SMB without reliable background interpolation field (e.g. from satellites, which is currently unavailable) is likely to fail. For example, the total accumulation over the GrIS based on such an interpolation [18] results in a value that is $40 \%$ lower that results from a regional climate model in Fig. 3.

\section{Conclusions and outlook}

At present, the balance state of the Greenland Ice Sheet (AIS) and its contribution to global sea level change are poorly known. The main reason for this is the uncertainty in the surface mass balance (SMB), a result of the chronic lack of SMB observations from sites with high accumulation (snowfall) and high ablation (melting and subsequent runoff). The large SMB gradients that occur in the coastal accumulation areas and the marginal ablation areas cannot be captured using simple parameterized melt models or global meteorological models at low resolution $(\sim 100 \mathrm{~km})$. Regional atmospheric climate modelling at high horizontal resolution (now approaching $10 \mathrm{~km}$ ) offers the right mix of realistic physics and the necessary resolution, if validated using the available measurements. Future research should focus on three things: 1) increase the number of SMB observations from zones with strong SMB gradients: these data will prove indispensible for validation of SMB models; 2) improve the representation of snow physics in existing meteorological models: these model should be capable of reliably simulating snowmelt, meltwater percolation and refreezing and albedo changes owing to metamorphosis; 3) couple regional atmosphere models to regional ocean models, in order to be able to assess the interaction of the ocean with the underside of the floating ice sheet (especially important in Antarctica).

\section{References}

1. J.L. Bamber, S. Ekholm, W.B. Krabill, J. Geophys. Res. 106, 6733 (2001)

2. J.M. Gregory, P. Huybrechts, S. Raper, Nature 428 (2004) doi:10.1038/428616a

3. B.R. Parizek, R.B. Alley, Quant. Sci. Rev. 23, 1013 (2004)

4. A. Cazenave, Science 314, 1250 (2006)

5. P. Lemke, J. Ren, R.B. Alley, I. Allison, J. Carrasco, G. Flato, Y. Fujii, G. Kaser, P. Mote, R.H. Thomas, T. Zhang, Climate Change 2007: The Physical Science Basis. Contribution of Working Group I to the Fourth Assessment Report of the Intergovernmental Panel on Climate Change, edited by S. Solomon, D. Qin, M. Manning, Z. Chen, M. Marquis, K.B. Averyt, M. Tignor, H.L. Miller (Cambridge University Press, UK, New York, USA, 2007)

6. Ramillien, G.A. Lombard, A. Cazenave, E.R. Ivins, M. Llubes, F. Remy, R. Biancale, Global Planet. Change 53, 198 (2006)

7. I. Velicogna, J. Wahr, Science 311, 1754 (2006) doi:10.1126/science.1123785

8. J.L. Chen, C.R. Wilson, B.D. Tapley, Science 313, 1958 (2006) doi:10.1126/science.1129007

9. S.B. Luthcke, H.J. Zwally, W. Abdalati, D.D. Rowlands, R.D. Ray, R.S. Nerem, F.G. Lemoine, J.J. McCarthy, D.S. Chinn, Science 314, 1286 (2006) doi:10.1126/science.1130776

10. W. Krabill, W. Abdalati, E. Frederick, S. Manizade, C. Martin, J. Sonntag, R. Swift, R. Thomas, W. Wright, J. Yungel, Science 289, 428 (2000)

11. H.J. Zwally, M.B. Giovinetto, J. Li, H.G. Cornejo, M.A. Beckley, A.C. Brenner, J.L. Saba, D. Yi, J. Glaciol. 51, 509 (2005)

12. O.M. Johannessen, K. Kirill, M.W. Miles, L.P. Bobylev, Science 310, 1013 (2005)

13. R. Thomas, E. Frederick, W. Krabill, S. Manizade, C. Martin, Geophys. Res. Lett. 33, L10503 (2006) 
14. E. Rignot, P. Kanagaratnam, Science 311, 986 (2006)

15. A. Shepherd, D. Wingham, Science 315, 1529 (2007) doi:10.1126/science.1136776

16. N.L. Bindoff, J. Willebrand, V. Artale, A. Cazenave, J.M. Gregory, S. Gulev, K. Hanawa, C. Le Quéré, S. Levitus, Y. Nojiri, C.K. Shum, L.D. Talley, A.S. Unnikrishnan, in Climate Change 200\%: The Physical Science Basis (Cambridge University Press, 2007), p. 385, ISBN: 0521705967

17. K. Steffen, J.E. Box, J. Geophys. Res. 106, 33951 (2001)

18. J.G. Cogley, J. Geophys. Res. 109, D18101 (2004)

19. H.J. Zwally, W. Abdalati, T. Herring, K. Larson, J. Saba, K. Steffen, Science 297 (2002) doi:10.1126/science. 1072708

20. I. Joughin, S.B. Das, M.A. King, B.E. Smith, I.M. Howat, T. Moon, Science 320, 781 (2008) doi:10.1126/science. 1153288

21. W. Krabill, E. Hanna, P. Huybrechts, W. Abdalati, J. Cappelen, B. Csatho, E. Frederick, S. Manizade, C. Martin, J. Sonntag, R. Swift, R. Thomas, J. Yungel, Geophys. Res. Lett. 31, L24402 (2004)

22. N. Reeh, Polarforschung 59, 113 (1991)

23. J. Oerlemans, H.F. Vugts, Bull. Amer. Meteorol. Soc. 74, 355 (1993)

24. R.S.W. Van de Wal, W. Greuell, M.R. van den Broeke, W. Boot, H. Snellen, C.H. Reijmer, J. Oerlemans, Ann. Glaciol. 42, 311 (2005)

25. M.R. Van den Broeke, C.J.P.P. Smeets, J. Ettema, C. van der Veen, R.S.W. van de Wal, J. Oerlemans, The Cryosph. Disc. 2, 711 (2008)

26. C.E. Bøggild, N. Reeh, H. Oerter, Glob. Planet. Change 9, 79 (1994)

27. R.J. Braithwaite, J. Glaciol. 41, 153 (1995)

28. R.S.W. Van de Wal, J. Oerlemans, Clim. Dynam. 13, 733 (1997)

29. M. Wild, P. Calanca, S.C. Scherrer, A. Ohmura, J. Geophys. Res. 108 (2003) doi: 10.1029/2002JD002451

30. E. Hanna, J. McConnell, S. Das, J. Cappelen, A. Stephens, J. Clim. 19, 344 (2006)

31. M. Bougamont, J.L. Bamber, W. Greuell, J. Geophys. Res. 110, F04018 (2005) doi:10.1029/2005JF000348

32. J.J. Cassano, J.E. Box, D.H. Bromwich, L. Li, K. Steffen, J. Geophys. Res. 106, 867 (2001)

33. K. Dethloff, M. Schwager, J.H. Christensen, S. Kiilsholm, A. Rinke, W. Dorn, F. JungRothenhäusler, H. Fischer, S. Kipfstuhl, H. Miller, J. Climate 15, 2821 (2002)

34. J.E. Box, D.H. Bromwich, B.A. Veenhuis, L.-S. Bai, J.C. Stroeve, J.C. Rogers, K. Steffen, T. Haran, S.-H. Wang, J. Climate 19, 2783 (2006)

35. X. Fettweis, The Cryosphere 1, 21 (2007) 